\title{
Enhancement of Incisional Wound Healing and Neovascularization in Normal Rats by Thrombin and Synthetic Thrombin Receptor-activating Peptides
}

\author{
D. H. Carney, ${ }^{\star}$ R. Mann, ${ }^{\star}$ W. R. Redin, ${ }^{\star}$ S. D. Pernia, ${ }^{\star}$ D. Berry, ${ }^{\star}$ J. P. Heggers, ${ }^{\ddagger}$ P. G. Hayward, ${ }^{\ddagger}$ M. C. Robson, ${ }^{\star}$ J. Christie, \\ C. Annable," J. W. Fenton II," and K. C. Glenn' \\ *Departments of Human Biological Chemistry and Genetics, ${ }^{\ddagger}$ Surgery, and \$Pathology, The University of Texas Medical Branch, \\ Galveston, Texas 77550; "Wadsworth Center for Laboratories and Research, New York State Department of Health, Albany, New York \\ 12201; Departments of Physiology and Cell Biology, and Biochemistry, The Albany Medical College of Union University, Albany, \\ New York 12208; and 'Monsanto Company, Chesterfield, Missouri 63198
}

\begin{abstract}
To better define thrombin-receptor interactions, we synthesized human thrombin peptides and identified binding-domain peptides that bind thrombin receptors and activate mitogenic signals (Glenn, K. C., G. H. Frost, J. S. Bergmann, and D. H. Carney. 1988. Pept. Res. 1:65-73). Treatment of full dermal dorsal incisions with a single topical application of thrombin receptor-activating peptide (TRAP-508) or human $\alpha$-thrombin in saline enhances 7-d incisional breaking strength in normal rats up to $82 \%$ or $55 \%$ over saline-treated controls, respectively. Control wounds require $\sim 11.5 \mathrm{~d}$ to achieve breaking strength equivalent to TRAP-treated wounds at day 7 . Thus, a single application of TRAP accelerates healing, shifting the time course forward by up to $4.5 \mathrm{~d}$. Histological comparisons at day 7 show more type I collagen, less evidence of prolonged inflammation, and an increase in number and maturity of capillaries in TRAP- and thrombin-treated incisions. Angiograms also show $50-65 \%$ more functional vascularization going across thrombin- and TRAP-treated surgical incisions. Thus, $\alpha$-thrombin and thrombin peptides, such as those released following injury, appear to initiate or enhance signals required for neovascularization and wound healing. The ability to accelerate normal wound healing events with synthetic peptides representing receptor binding domains of human thrombin may offer new options for management of wound healing in man. (J. Clin. Invest. 1992. 89:1469-1477.) Key words: growth factors • hemostasis • dermal injury • angiogenesis $•$ collagen

\section{Introduction}

Therapeutic options for treating both normal and healing-impaired wounds may soon include modulation of various processes involved in tissue repair. One way of realizing this particular goal of wound healing research is to enhance normal healing events using naturally occurring stimulatory components or synthetic peptides representing domains of factors which interact with mitogenic or chemotactic receptors (1).

Address correspondence to Dr. Darrell H. Carney, Department of Human Biological Chemistry and Genetics, The University of Texas Medical Branch, Galveston, TX 77550.

Received for publication 8 October 1991 and in revised form 18 December 1991.

J. Clin. Invest.

(c) The American Society for Clinical Investigation, Inc.

0021-9738/92/05/1469/09 \$2.00

Volume 89, May 1992, 1469-1477
A number of endogenous growth factors have been implicated as possible modulators of wound healing. Early studies showed that addition of activated macrophages to wounds enhances early tissue repair $(2,3)$. More recently, it was shown that macrophages isolated from wound chambers express mRNA for transforming growth factor- $\alpha$, transforming growth factor- $\beta$ (TGF- $\beta$ ), ${ }^{1}$ platelet-derived growth factor (PDGF), epidermal growth factor (EGF), and insulin-like growth factor-1 (4). A number of these factors are currently being tested in animal models and in clinical trials to determine their effects on wound healing $(5,6)$.

One animal model which has been used as an indicator of possible efficacy for surgical wounds is the treatment of surgical incisions in rats with growth factors and measurement of the recovery of incisional breaking strength (7-11). In this model, addition of TGF- $\beta$, PDGF, and EGF at the time of surgery is effective only when factors are administered in collagen gel ( 7 , 8 ) or slow release vesicles (11). Modest increases in breaking strength have been achieved with multiple saline applications of EGF (11) or with single injections of fibroblast growth factor (9), or TGF- $\beta$ (10), into the skin adjacent to the wound three days after surgery. Because collagen matrix addition to wounds or injection or factors subsequent to surgery may complicate normal healing, the search has continued for an effective modulator of wound healing that can initiate or potentiate early local healing events with a simple single application.

One growth factor present at the site of tissue injury that may have been overlooked in early searches for modulators of wound healing is thrombin. In addition to its well documented role in the formation of fibrin clots and platelet activation, thrombin is known to interact with many cell types which are involved in both early and late stages of wound healing. Thrombin initiates early vascular changes including: increased vascular permeability, allowing cells and fluid to enter the wounded tissue (12); endothelial cell synthesis and release of c-sis or PDGF (13-15); increased adherence of platelets and neutrophils to endothelial cells (16-20); and increased adherence of monocytes and $T$ cells to endothelial cells (21). The increased adherence of circulating cells to capillaries may be essential in establishing an inflammatory response which then initiates subsequent events leading to neovascularization and fibroblast proliferation.

In addition to these early microvascular effects, thrombin has direct effects on inflammatory cells, fibroblasts, and endo-

1. Abbreviations used in this paper: EGF, epidermal growth factor; PDGF, platelet-derived growth factor; TGF- $\beta$, transforming growth factor- $\beta$; TRAP, thrombin receptor-activating peptide. 
thelial cells. For example, thrombin stimulates chemotaxis and aggregation of neutrophils (22), lymphocytes (23), and monocytic cells $(24,25)$; activates T cells causing both a proliferative response and release of IL-6 (26); and stimulates proliferation of fibroblasts (27-30), epithelial cells (31), and endothelial cells (32-34). Thus, thrombin or portions of thrombin molecules released from fibrin clots (35) or subendothelial matrix (36), may play an important role in initiating early cellular events in tissue repair.

Many of these cellular postclotting effects of thrombin appear to be mediated through interaction with high affinity receptors which have been identified on fibroblasts (37-40), capillary endothelial cells (34), keratinocytes (McCaully, R. L., M. C. Robson, and D. H. Carney, unpublished observations), monocytes $(24,41)$, and neutrophils (42). A unique functional receptor for thrombin has now been cloned confirming the specificity and potential physiological significance of these interactions (43).

To better define the interaction of thrombin with its receptor, we synthesized a number of peptides representing potential thrombin-receptor binding domains (1). One of the synthetic thrombin peptides representing residues 508-530 of human prothrombin was shown to bind to thrombin receptors and activate receptor-mediated mitogenic signals (1). We have thus referred to this peptide as the thrombin receptor-activating peptide (TRAP). The present study investigates the potential efficacy of purified human $\alpha$-thrombin and TRAP-508 in promoting tissue repair following surgical incisions in rats.

\section{Methods}

Thrombin and TRAP-508. Highly purified human $\alpha$-thrombin $(\sim 2,800 \mathrm{NIH}$ units/mg) was prepared as described by Fenton et al. (44). Purified thrombin $(1-2 \mathrm{mg} / \mathrm{ml})$ was stored at $-80^{\circ} \mathrm{C}$ in $150 \mathrm{mM}$ phosphate buffer with $750 \mathrm{mM} \mathrm{NaCl}$ at $\mathrm{pH} \sim 6.5$, or as working solution $(200 \mu \mathrm{g} / \mathrm{ml})$ aliquots in PBS at $\mathrm{pH}$ 7.4. Thrombin prepared and handled in this manner stimulates proliferation of cultured fibroblasts and binds to thrombin receptors on these cells with a $K_{\mathrm{d}}$ of $\sim 2 \times 10^{-9}$ M (32).

The thrombin receptor-activating peptide, TRAP-508, (AGYKPDEGKRG-DACEGDSGGPFV) representing amino acids 508-530 of human prothrombin, and control peptides were synthesized as previously described (1), on a Biosearch 9600 automated peptide synthesizer in the University of Texas Medical Branch Peptide-DNA Synthesis Laboratory. TRAP-508b (AGYKPGEGKRGDACEGDSGGPFV), representing the TRAP region of bovine prothrombin was synthesized in the same manner by Monsanto Co. using a synthesizer (Applied Biosystems, Inc., Foster City, CA). In all cases, synthesis used T-boc amino acids, hydrogen fluoride cleavage, and deblocking. After purification on reverse phase HPLC, peptides were lyophilized and stored as a powder at $-20^{\circ} \mathrm{C}$. Working stocks of peptide were prepared by diluting the peptides to $200 \mu \mathrm{g} / \mathrm{ml}$ in PBS and were stored frozen at $-80^{\circ} \mathrm{C}$. Both of these peptides have been shown to compete with thrombin for receptor binding and activation with an apparent affinity of from 15 to $100 \mathrm{nM}$ (1, and unpublished). Thus, for initial studies TRAP-508 was used at concentrations $\sim 50$-fold higher than that of $\alpha$-thrombin.

Experimental design. Acclimatized adult male Harlan SpragueDawley rats weighing 250-300 g were anesthetized (pentobarbital 35 $\mathrm{mg} / \mathrm{kg}$ i.p.) and their backs were clipped and depilated (Surgex depilatory; Epcon Medical Systems Inc., Livermore, CA). A single 6-cm vertical incision was made on the dorsal midline or a parallel pair of $6-\mathrm{cm}$ incisions were cut $\sim 1.5 \mathrm{~cm}$ to either side of the midline. These incisions began immediately inferior to the tips of the scapulae and extended caudally. Each incision was cut through the panniculus carnosus exposing the underlying fascia and muscle layer with a skin separation of at least $1 \mathrm{~cm}$. Hemostasis was achieved by even compression with a gauze sponge. The wound was closed with three simple interrupted sutures (4-0 Ethilon; Ethicon, Inc., Somerville, NJ) placed $1.5 \mathrm{~cm}$ apart. Unless indicated each incision received a single topical treatment of PBS vehicle $(\sim 7 \mu \mathrm{l} / \mathrm{cm})$, or PBS containing purified human $\alpha$-thrombin $(333 \mathrm{ng}$ or $10 \mathrm{pmol} / \mathrm{cm})$ or the synthetic peptide TRAP-508 $(1.33 \mu \mathrm{g}$ or $500 \mathrm{pmol} / \mathrm{cm})$.

Rats were housed in individual cages (with elevated stainless steel floors for the first three postoperative days) and allowed food and water ad lib. After 7, 14, or 21 days, rats were killed with an overdose of pentobarbital $(100 \mathrm{mg} / \mathrm{kg}$ i.p.), dorsal skins were removed, and 0.8 $\times 4-\mathrm{cm}$ full dermal strips were cut perpendicular to the incision between the sutures (two strips per incision). Incisional breaking strength measurements were made on these strips using a tensiometer (Model 4205; Instron Corp., Canton, MA) with 5-kg load cell and crosshead speed of $10 \mathrm{~mm} / \mathrm{min}$. Samples were taken from adjacent areas of the incision for histology. All procedures were performed in approved facilities with University of Texas Medical Branch Animal Care and Use Committee approval of all protocols to insure that animals were not wasted or subjected to unwarranted stress.

Histology. Specimens were placed in $10 \%$ neutral buffered formalin, processed through paraffin, and sectioned. A modification of the Movat pentachrome stain was used to distinguish between type I and type III collagen (45). Histological examination and numerical scoring of cellular and tissue parameters of wound healing in slides from control-, TRAP-508-, and thrombin-treated incisions was done by two pathologists in blinded fashion unaware of treatment groupings. Photographs of histological sections were taken through a Nikon Labphot Microscope using Kodak Ektachrome $50 \mathrm{~T}$ with identical exposures.

Angiography. At the time of sacrifice, the animals were injected with an overdose of pentobarbital $(70 \mathrm{mg} / \mathrm{kg}$ i.p.), laparotomy was performed, and the descending aorta was cannulated with a 24-guage catheter (Quick-Cath; Travenol Laboratories, Deerfield, IL). The inferior vena cava was transected above the diaphragm to reduce back pressure. Approximately $10 \mathrm{ml}$ of radiopaque dye (a 1:3.5 mixture of mucilage acacica [ $85 \%$ sucrose and $10 \%$ acacia wt/vol in $\mathrm{H}_{2} \mathrm{O}$ ] and barium sulfate-gelatin [ $43 \%$ barium sulfate and $4.3 \%$ gelatin wt/vol in $\mathrm{H}_{2} \mathrm{O}$ ], prepared and maintained at $37^{\circ} \mathrm{C}$ ), was injected into the aorta until pink dye could be seen in the capillary network of the exposed organs and dye flowed freely from the cut vena cava. The aorta and vena cava were then tied off and the animals were cooled to $5^{\circ} \mathrm{C}$ to set the gel. After 30 min the dorsal skin was removed, pinned to cork boards, and fixed in $10 \%$ neutral buffered formalin. Roentgenography was performed 4-16 h after fixation using Kodak X-O-Mat film with 20 kilovolt, 500 milliamperes/second exposure at 36-in focus using a beryllium window. Positive photographs were made directly from $\mathrm{x}$ ray film to preserve fine detail.

Video graphics analysis of incisional areas was performed with JAVA Software (Jandel Scientific, Corte Madera, CA) to determine the number of radiopaque capillaries crossing the incision (a strip $0.1 \times 6$ $\mathrm{cm}$ ) and the number of radiopaque capillaries within $0.4 \mathrm{~cm}$ of the incision (an area $0.8 \times 6 \mathrm{~cm}$ ).

Statistical analysis. Data were analyzed using a one-way analysis of variance to compare differences between groups. Statistical significance was defined as $P$ value $<0.05$.

\section{Results}

Effects of thrombin and TRAP-508 on incisional breaking strength. To determine the efficacy of thrombin and TRAP508 as possible modulators of wound healing, single $6-\mathrm{cm}$ full dermal incisions were cut through the backs of rats and the amount of healing relative to PBS controls was determined by measuring the breaking strength of the closed incision after 7 , 14 , or 21 days. This model was chosen since it has been used extensively to evaluate the potential of other growth factors (7-11). In our experiments, the test substances were applied in a single application of PBS at the time of closure. 
After seven days, incisions treated with a single application of $\alpha$-thrombin ( $10 \mathrm{pmol}$ or $0.33 \mu \mathrm{g} / \mathrm{cm}$ of incision) showed a $26 \%$ increase in breaking strength over those treated with PBS alone with a $P$ value of $<0.013$ (Fig. $1 A$ ). Unexpectedly, a single application of TRAP-508 worked even better than thrombin increasing breaking strength $41 \%$ over controls $(P$ $<0.001$, at $500 \mathrm{pmol} / \mathrm{cm}$ ). These data represent the combination of data collected from four different experiments with a total of 86 rats. Enhancement by TRAP in individual experiments ranged from $\sim 30$ to $70 \%$ over controls. Enhancement was dose dependent for thrombin and TRAP-508, showing apparent maximal stimulation with addition of $5-50 \mathrm{pmol} / \mathrm{cm}$ of thrombin or $130 \mathrm{pmol}(0.33 \mu \mathrm{g}) / \mathrm{cm}$ of TRAP-508 (Fig. $1 B$ ). The slightly higher concentration of peptide required for maximal effectiveness, relative to thrombin, correlates with the observed differences in affinity of thrombin and TRAP for receptor binding (1). These experiments indicate that TRAP-treated wounds were slightly stronger than thrombin-treated wounds and that this difference could not be overcome by increasing thrombin concentration since higher concentrations appeared to become inhibitory.

To follow the time course of the healing of these incisions, two parallel incisions were cut on each animal, both incisions were treated with the same coded substance (PBS, $\alpha$-thrombin,
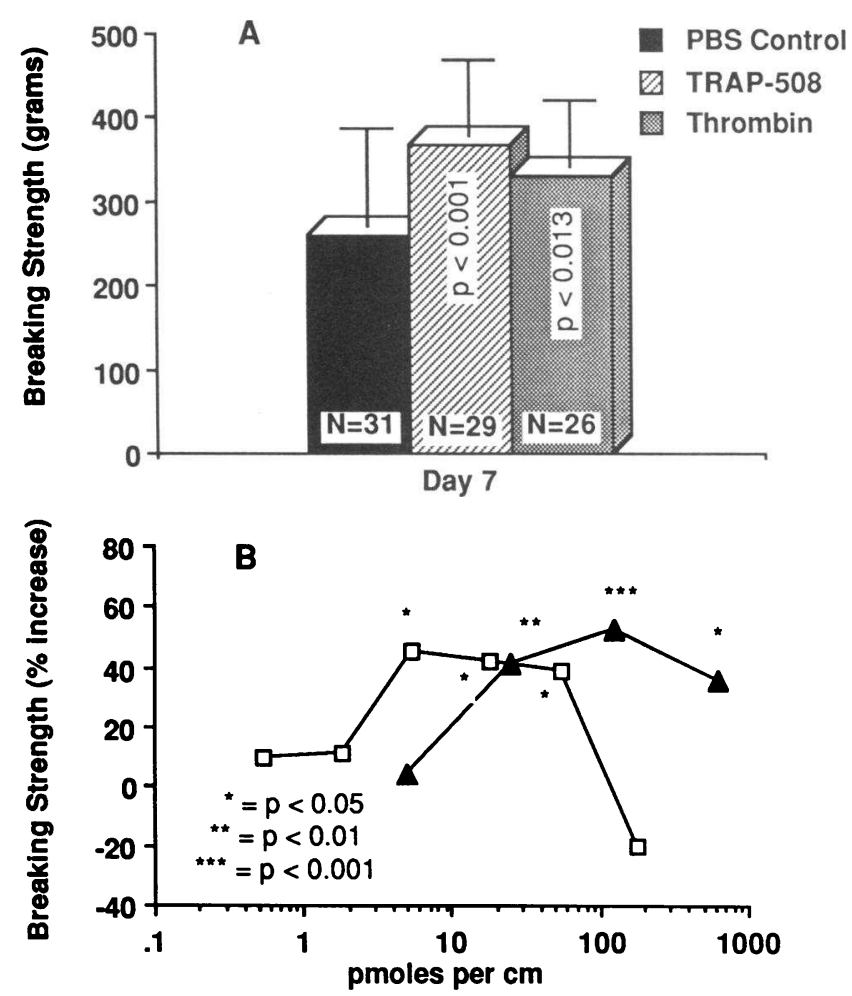

Figure 1. Effect of thrombin and TRAP-508 on 7-d incisional breaking strength. Single 6-cm incisions were cut on the dorsal midline of rats through the panniculus carnosus as described in Methods. Incisions were coapted with three interrupted sutures and treated with a single topical application of $40 \mu \mathrm{l}$ of control PBS, thrombin (10 $\mathrm{pmol} / \mathrm{cm})$, or TRAP-508 $(500 \mathrm{pmol} / \mathrm{cm}, A$; or indicated concentrations, $B$ ). After $7 \mathrm{~d}$, animals were killed and two $0.8 \times 4.0-\mathrm{cm}$ strips were cut between the sutures perpendicular to the incision. Incisional breaking strength was determined using an Instron Tensiometer as described in Methods. Error bars indicate 1 SD from the mean ( $n$ $=26-31$ ). or TRAP-508b), and breaking strength was determined at day 7,14 , and 21 (Fig. 2). As shown in Fig. $2 A$ and $B$, TRAP-508b, increased breaking strength $>80 \%$ over control values at day 7 $(P<0.001)$. A significant effect of TRAP-508b was also observed at day 14 and 21 , with $39 \%(P<0.001)$ and $18 \%(P$ $<0.002$ ) increases over control breaking strength, respectively. Thus, the enhancement of healing appears to be most obvious during early healing with controls catching up after two or three weeks. In these experiments, $\alpha$-thrombin increased incisional breaking strength $\sim 60 \%$ as well as TRAP-508b at day 7 and day 14 , but was not significantly different from controls at day 21. At these concentrations of thrombin (which appeared maximal, Fig. $1 B$ ), the peptide was significantly better than thrombin at day $14(P<0.03)$ and day $21(P<0.005)$. It is interesting to note that in these experiments control incisions appear to take $\sim 11.5$ days to achieve the same breaking strength as that observed in TRAP-treated wounds at day 7. This suggests that the single topical application of TRAP has accelerated the healing process by $\sim 4.5$ days in these animals.

To test the specificity of the TRAP effect, additional peptides have been synthesized and applied to incisions. As shown in Table I, neither a truncated form of TRAP (representing amino acids 514-524 containing the RGD portion of TRAP508), nor a nonrelated peptide (peptide P-19), is effective in increasing breaking strength over that of control saline. Although additional peptides must be tested to define specific required amino acids, these results indicate that enhanced breaking strength cannot be achieved with random peptides or a peptide missing major portions of the unique TRAP sequence.

Thrombin and TRAP effects on cellular and histological parameters of wound healing. Histology demonstrated a more advanced state of healing in both $\alpha$-thrombin- and TRAP-508treated incisions at day 7. Movat stained sections (45), which differentiate between type I and type III collagen, reveal increased amounts of mature type I collagen (which stains yellow), compared to type III collagen (which stains green) in both TRAP-508 (Fig. $3 B$ ) and thrombin (Fig. $3 C$ ) treated incisions relative to PBS controls (Fig. $3 A$ ). This color difference can be observed both near the epithelial surface (Fig. $3 A^{\prime}, B^{\prime}$, and $C^{\prime}$ )

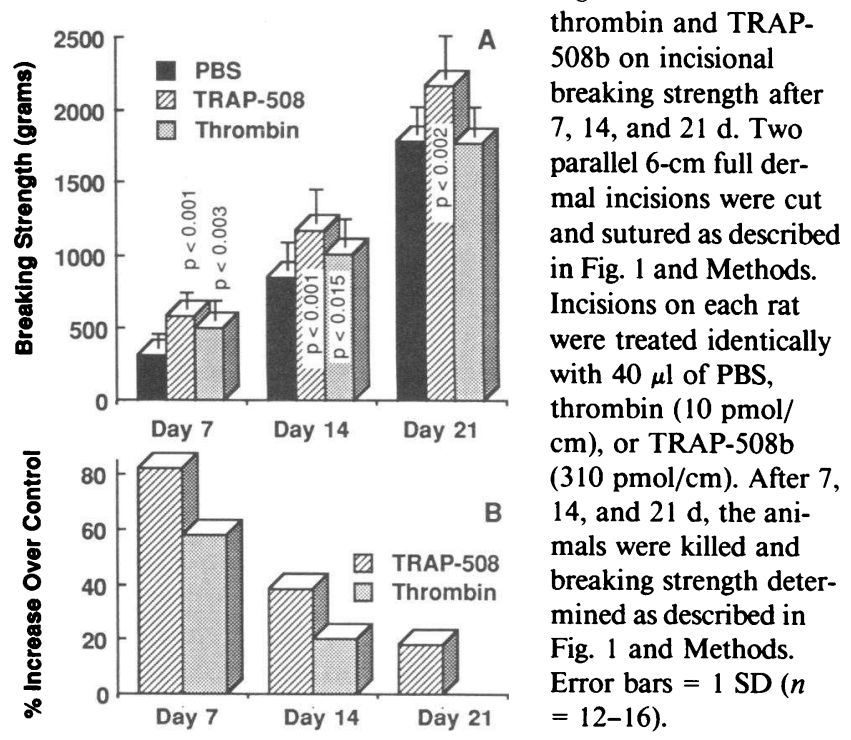

Figure 2. Effects of thrombin and TRAP( breaking strength after 7,14 , and $21 \mathrm{~d}$. Two parallel 6-cm full dermal incisions were cut and sutured as described in Fig. 1 and Methods Incisions on each rat were treated identically with $40 \mu 1$ of PBS thrombin $(10 \mathrm{pmol} /$ $\mathrm{cm})$, or TRAP-508b (310 pmol/cm). After 7 , 14 , and $21 \mathrm{~d}$, the animals were killed and breaking strength deteras described in $=12-16$ ). 
Table I. Specificity of TRAP-508 Enhancement of Incisional Breaking Strength*

\begin{tabular}{ll}
\hline \multicolumn{1}{c}{ Treatment } & Ratio test/Saline Control \\
\hline TRAP analogue p514-523 (EGKRGDACEG) & $0.97 \pm 0.25(n=5)$ \\
Peptide P-19 (APRLRFKPIC) & $1.03 \pm 0.31(n=4)$ \\
TRAP-508 (AGYKPDEGKRGDACEGDSGGPFV) & $1.37 \pm 0.39(n=6)$
\end{tabular}

* Two parallel 6-cm full dermal incisions were cut through the backs of anesthetized and depilitated rats as described in Methods. The incisions were closed with three interrupted sutures and treated on alternating sides with $40 \mu$ l of PBS alone (control) or PBS plus test peptide (1.3 $\mu \mathrm{g} / \mathrm{cm})$. After 14 days, rats were killed and incisional breaking strength was measured as described in Methods. Controls for this experiment averaged $0.96 \pm 0.38 \mathrm{~kg}(n=14)$. TRAP-508 enhancement relative to combined control data $(P<0.02)$.

and in the region adjacent to the panniculus carnosus (Fig. 3 $A^{\prime \prime}, B^{\prime \prime}$, and $\left.C^{\prime \prime}\right)$. Other notable signs of more advanced healing in TRAP- and thrombin-treated incisions include increased cellularity, more collagen and matrix around each cell (less apparent open space), less inflammation, and increased numbers and maturation of capillaries, especially in the lower levels of wounds near the panniculus carnosus (compare Fig. 3, $A^{\prime \prime}$, $B^{\prime \prime}$, and $C^{\prime \prime}$, and Fig. $4, A, B$, and $C$ ).

To estimate the degree of healing in these incisions, histological sections were prepared from paired incisions treated with $\alpha$-thrombin, TRAP-508, or PBS as described in Table I. Specimens were removed from the rats and both Movat and hematoxilyn-stained sections were examined and scored independently (in blinded fashion) by two pathologists. Each section was scored numerically from 0 to 5 for number of inflammatory cells, amount of type I and type III collagen, number of fibroblasts, and number of capillaries ( 0 representing no visible effects of healing or specific cell types and 5 representing the maximal possible number of cells or healing equivalent to uninjured skin).

A striking difference was observed in the number of inflammatory cells in these sections (Table II). PBS controls had an average value of 1.25 , which relates to $\sim 45-50$ inflammatory cells observed in a $0.02-\mathrm{mm}^{2}$ grid projected over sections adjacent to the panniculus carnosus. These PBS section scores ranged to $3+$, or $>200$ inflammatory cells per grid. $\alpha$-Thrombin-treated wounds had some inflammation $(0.83$, representing $\sim 25$ cells per grid, with scores ranging from 0 to 2 ). In contrast, TRAP-508-treated incisions showed almost no inflammation $(0.30$, or $\sim 10$ inflammatory cells per grid with scores ranging from 0 to 1 ).

It should be noted that inflammation represents the earliest stage of wound healing, with inflammatory cells insuring protection from infection and release of chemotactic and mitogenic factors. This phase declines with progression of proliferative and maturation phases of healing. In open wounds, TRAP508 enhances recruitment of neutrophils within the first few hours after wounding (unpublished). Thus, the decreased inflammation observed in 7-d TRAP-508-treated incisions suggests that the inflammatory stage of healing has already occurred and the wounds have progressed into a proliferative or maturation phase.

The amount of type I collagen scored in sections from TRAP-508- and $\alpha$-thrombin-treated incisions was more than two times the amount observed in control sections (Table II). The relative number of fibroblasts in these sections, however, was similar to the number observed in controls (data not shown). Thus, TRAP-508 and thrombin appear to increase production of mature collagen without producing abnormally high numbers of fibroblasts. This again indicates a more advanced, but normal sequence of healing. This may be important since increasing the proliferation of specific cell types may result in abnormal healing or scar formation $(46,47)$.

The number and maturity of capillaries in the healing wounds was increased in sections from TRAP-508- and $\alpha$ thrombin-treated incisions by nearly $50 \%$ over control incisions (Table II). This difference and a demonstration of the enhanced maturity of capillaries can be seen by comparing treated and control samples in lower regions of the healing dermis (Figs. 3" and 4). These capillaries and blood vessels also appear more mature in that they have thicker walls, more red blood cells, and less evidence of edema or inflammatory cell accumulation in the adjacent tissue. A difference is also observed in the amount of type I collagen in the tissue surrounding these functioning blood vessels. Thus, a major mechanism of TRAP-508 and thrombin enhancement of breaking strength and healing of these incisions may be related to their effects on neovascularization or angiogenesis.

Only slight histological differences were observed at day 14 and 21 (data not shown). At day 14, these included: increased collagen and cellularity in TRAP-508-treated incisions at the level of the panniculus: a more intact panniculus with less evidence of deterioration in TRAP-treated incisions relative to controls; and the appearance of lingering inflammatory cells at or below the panniculus in control and thrombin-treated incisions (but not in TRAP-treated incisions). By day 21, a continuous panniculus carnosus was observed below each wound and a predominance of mature type I collagen was seen in all samples. Consistent with incisional breaking strength, after 21 days, the control incisions appear to "catch up" with those treated with TRAP or thrombin.

Analysis of neovascularization using angiography. Full dermal incisions were made and treated with a single application of TRAP, thrombin, or PBS as described above. On day 7, the rats were deeply anesthetized and a radiopaque barium sulfate dye was injected into the descending aorta. After perfusing the circulatory system, the rats were prepared for angiography as described in Methods.

As shown in Fig. $5 A$, the region underneath or through the dorsal midline incision of control wounds appears to be devoid of new vessel growth. In contrast, incisions treated with TRAP508 exhibit a complex network of vessels approaching and traversing the area of the incision (Fig. $5 \mathrm{~B}$ ). As in the breaking strength and histology, incisions treated with thrombin show increased neovascularization relative to controls, but not as much vascular development as the TRAP-508-treated wounds 

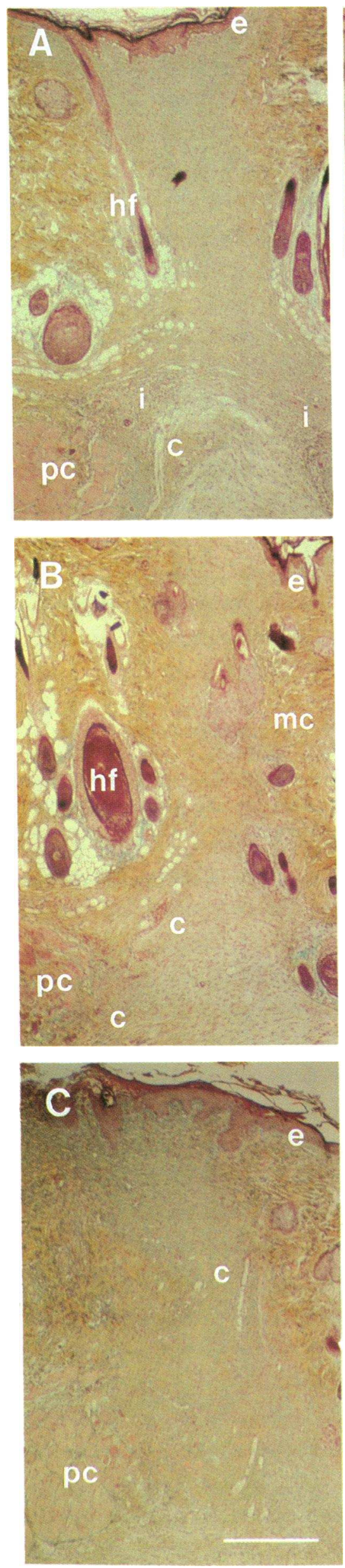
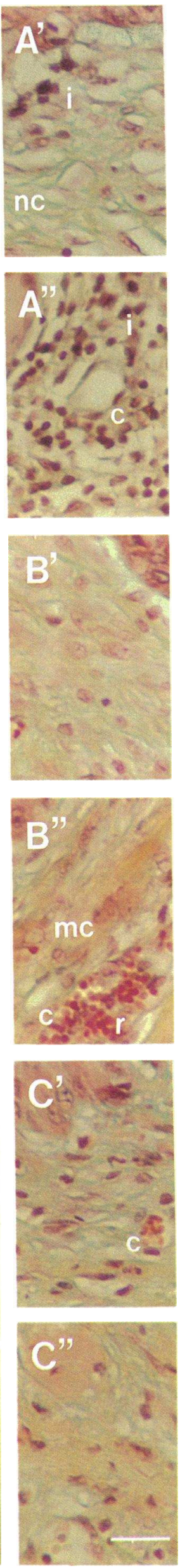

Table II. Blinded Analysis of Histological Sections Seven Days after Incision*

\begin{tabular}{lccc}
\hline \multicolumn{1}{c}{ Treatment } & Inflammation $^{\ddagger}$ & Type I collagen $^{8}$ & Capillaries" \\
\hline Control PBS & $1.25 \pm 0.95$ & $1.10 \pm 0.55$ & $1.80 \pm 1.30$ \\
Thrombin & $0.83 \pm 0.75$ & $2.25 \pm 0.50$ & $3.00 \pm 0.11$ \\
TRAP-508 & $0.30 \pm 0.44$ & $2.50 \pm 0.63$ & $2.75 \pm 0.95$
\end{tabular}

* Histological sections were cut perpendicular to incisions treated with PBS, thrombin, or TRAP-508 as described in Fig. 1. Sections were stained with Movat stain (45) and examined by two pathologists without knowledge of treatment groups. Each section was scored with a numerical score from 0 to 5 , with a score of 5 representing the maximal number of cells or tissue maturity relative to normal skin. $n=4-8$ sections for each treatment.

‡ Number of PMN's, monocytes, and lymphocytes observed both near the wound surface and at the level of the panniculus carnosus.

${ }^{8}$ Type I collagen was scored based on the amount of yellow staining type I collagen (45) and the maturity of the collagen bundles.

"Capillaries were scored at and just below the level of the panniculus carnosus.

(Fig. $5 \mathrm{C}$ ). Since the radiopaque dye is pumped only into functional vessels and microvasculature, these results provide a direct demonstration that TRAP-508 and thrombin stimulate neovascularization in these healing wounds.

As shown in Table III, graphics analysis of 7-d angiograms from 14 rats ( 4 or 5 rats per treatment group) indicate an average of 14.5 functional blood vessels crossing the incisional midline in TRAP-treated incisions compared with 12.5 in thrombin-treated incisions and only 8.7 in incisions treated with PBS alone. Thus, by these criteria, TRAP-508 appears to increase neovascularization by $67 \%(P<0.03)$. If one counts the total number of functional blood vessels within a $0.8 \times 6-\mathrm{cm}$ area surrounding the original incision, TRAP- and thrombintreated rats are only slightly higher than the controls (Table III). Thus, the differences observed in number of capillaries crossing the midline does not reflect differences in amount of dye perfused into the animal backs.

To further exclude variation in amount of dye injected per animal, additional experiments were performed with two incisions per rat; one control incision and one TRAP-treated incision per animal. After 14 days, angiography was performed and

Figure 3. Effect of thrombin and TRAP-508 on histology of 7-d incisions. Dorsal surgical incisions prepared as described in Fig. 1 were treated topically at closure with: $(A)$ PBS $40 \mu \mathrm{l}$, as a control; $(B)$ TRAP-508, $500 \mathrm{pmol} / \mathrm{cm}$; and $(C)$ thrombin, $10 \mathrm{pmol} / \mathrm{cm}$. After 7 $\mathrm{d}$, the animals were killed and histological sections, cut perpendicular to the incisions, were prepared as described in Methods. These sections were stained with a modified Movat stain (45) to distinguish between mature type I collagen (which stains yellow) and type III collagen (which stains green). Large panels $(A, B, C)$ are low magnification ( $4 \times$ objective) photographs of entire dermal layer (Bar in panel $C=400 \mu \mathrm{m})$; smaller panels $\left(A^{\prime}, B^{\prime}, C^{\prime}\right)$ and $\left(A^{\prime \prime}, B^{\prime \prime}, C^{\prime \prime}\right)$ are higher magnification (40X objective) of area just under epithelial layer and adjacent to the panniculus carnosus, respectively. (Bar in panel $C^{\prime \prime}$ $=25 \mu \mathrm{m})$. epithelium (e); panniculus carnosus ( $p c)$; hair follicles $(h f)$; capillaries $(c)$; mature type I collagen $(m c)$; type III collagen $(n c)$; leukocytic inflammatory cells $(i)$; and red blood cells $(r)$. 

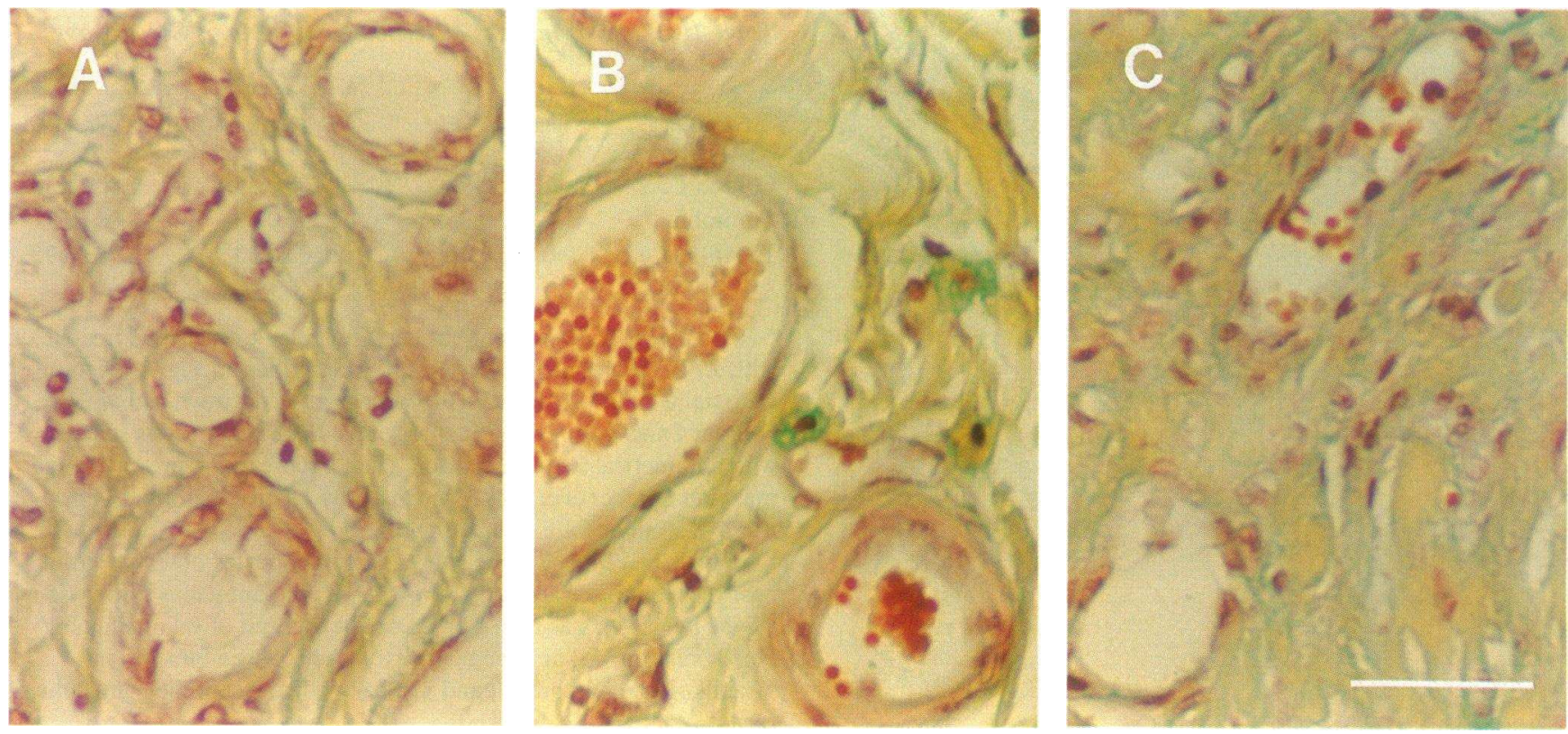

Figure 4. Effect of TRAP-508 and thrombin on neovascularization in the lower dermis. Histological sections were prepared with Movat stain at day 7 as described in Fig. 3. Photographs of the incisional region just under the panniculus carnosus (see Fig. 3) were taken to demonstrate microvascular maturity and function (presence of red blood cells). $(A)$ PBS; $(B)$ TRAP-508; and $(C)$ thrombin. (Bar in panel $C=40 \mu \mathrm{M}$ ).

incisional breaking strength was determined on each incision. An example of these experiments is shown in Fig. 6. As in experiments with single incisions, TRAP-508-treated wounds have extensive vascularization in the incisional area relative to control incisions. Breaking strength of these same incisions show that the TRAP-treated incision is $\sim 45 \%$ stronger than the control incision (Fig. 6). Thus, we can demonstrate on a single rat a correlation between TRAP enhancement of breaking strength and neovascularization.

\section{Discussion}

The role of thrombin in hemostasis is well established (48). However, the potential extent of its involvement in mediating various cellular and platelet responses to injury is only beginning to be understood. With the discovery of high affinity thrombin receptors on fibroblasts (37-42) and other cells (reviewed in references 49 and 50) and the recent cloning of a functional thrombin receptor (43), it is becoming clear that
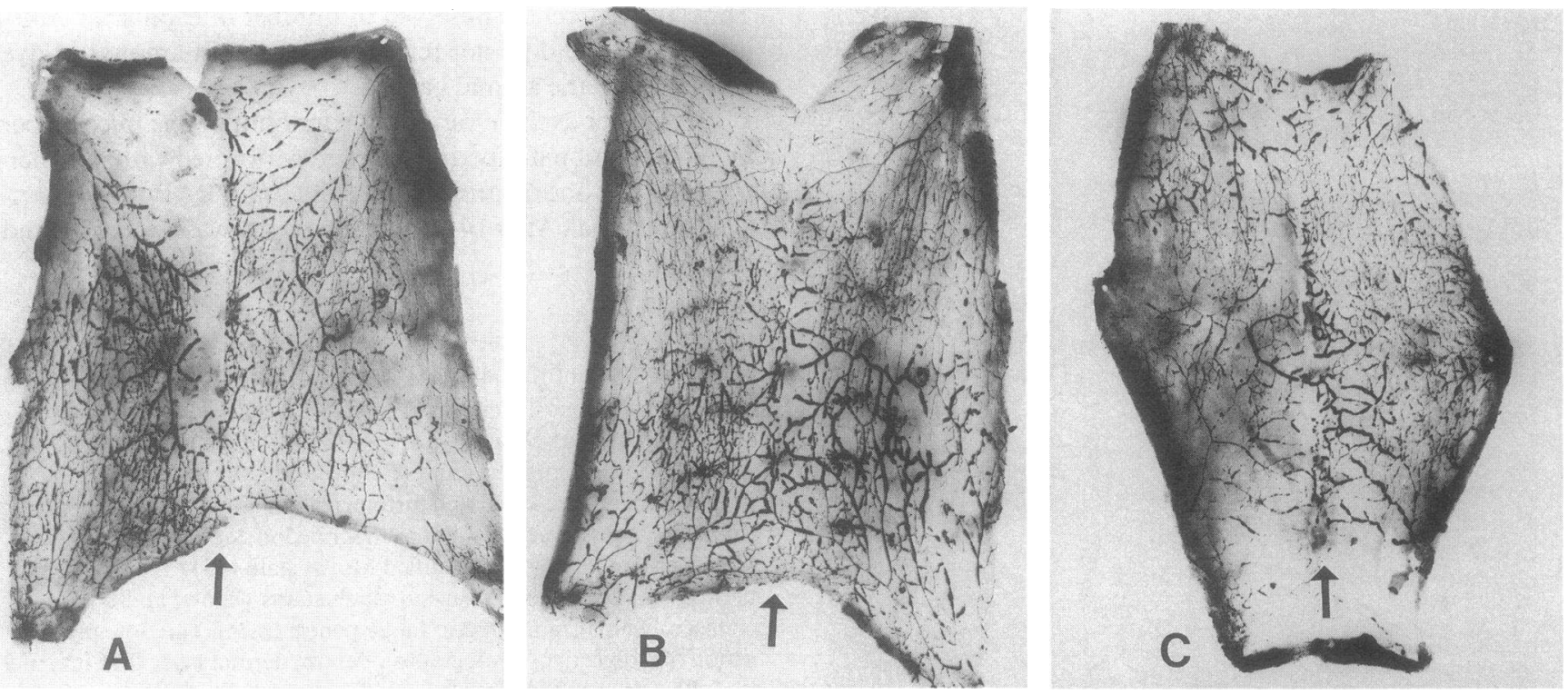

Figure 5. Effect of TRAP-508 and thrombin on neovascularization and vascular passivity as determined by angiography. Single dorsal midline incisions were cut and treated with PBS $(A)$, TRAP-508, $(B)$, or thrombin $(C)$ as described in Fig. 1 . After seven days, rats were anesthetized and radiopaque dye was injected into their circulatory system as described in Methods. Rat backs were then removed and x-rayed to determine the extent of functional vasculature in incisional areas. Rat backs are aligned with the cephalic region at the top of the figure. Arrows at the bottom (caudal) indicate the location and direction of midline dorsal incisions. 
Table III. Effect of Thrombin and TRAP-508 on Neovascularization of Incisional Wounds*

\begin{tabular}{lrccc}
\hline Treatment & $\begin{array}{c}\text { Capillaries } \\
\text { crossing incision } \\
(0.1 \times 6 \text {-cm strip) }\end{array}$ & $\begin{array}{c}\text { Percentage of } \\
\text { control }\end{array}$ & $\begin{array}{c}\text { Capillaries } \\
\text { in incisional } \\
\text { area }(0.8 \times 6 \mathrm{~cm})\end{array}$ & $\begin{array}{c}\text { Percentage of } \\
\text { control }\end{array}$ \\
\hline PBS & $8.7 \pm 33(n=5)$ & - & $46.6 \pm 13.8(n=5)$ & - \\
TRAP-508 & $14.5 \pm 2.8(n=4)$ & $167(P<0.03)$ & $59.8 \pm 26.3(n=4)$ & 128 (NS) \\
Thrombin & $12.5 \pm 3.2(n=5)$ & 144 (NS) & $49.0 \pm 13.5(n=5)$ & 105 (NS) \\
\hline
\end{tabular}

* Full dermal dorsal incisions were treated and prepared for angiography as described in Fig. 5. After development, films were coded and incisional regions were analyzed by video graphics analysis (JAVA, Jandel Scientific) to estimate the number of functional capillaries carrying radiopaque dye into $(0.8 \times 6-\mathrm{cm}$ area $)$ or across $(0.1 \times 6-\mathrm{cm}$ strip $)$ the incisional space. Each angiogram was analyzed three times and averaged to insure that the area chosen was representative. Numbers represent the mean \pm 1 SD of $n=4$ or 5 separate angiograms.

thrombin initiates a number of cellular postclotting events previously assumed only to be initiated by other growth factors. Recent studies showed that synthetic peptides representing the high affinity binding domain of thrombin could interact with thrombin receptors and enhance thrombin simulated mitogenesis (1). This suggested that these thrombin receptor-activating peptides might be useful in vivo to mimic the natural effects of thrombin interaction with receptors on various types of cells.

The present study reports significant increases in incisional breaking strength over controls in wounds treated with a single application of human $\alpha$-thrombin or the synthetic peptide, TRAP-508. The increase in breaking strength correlates with histological findings of more advanced stages of wound healing with fewer inflammatory cells, more type I collagen relative to matched saline-treated control incisions after seven days, and increased capillary growth and maturation in both thrombin-
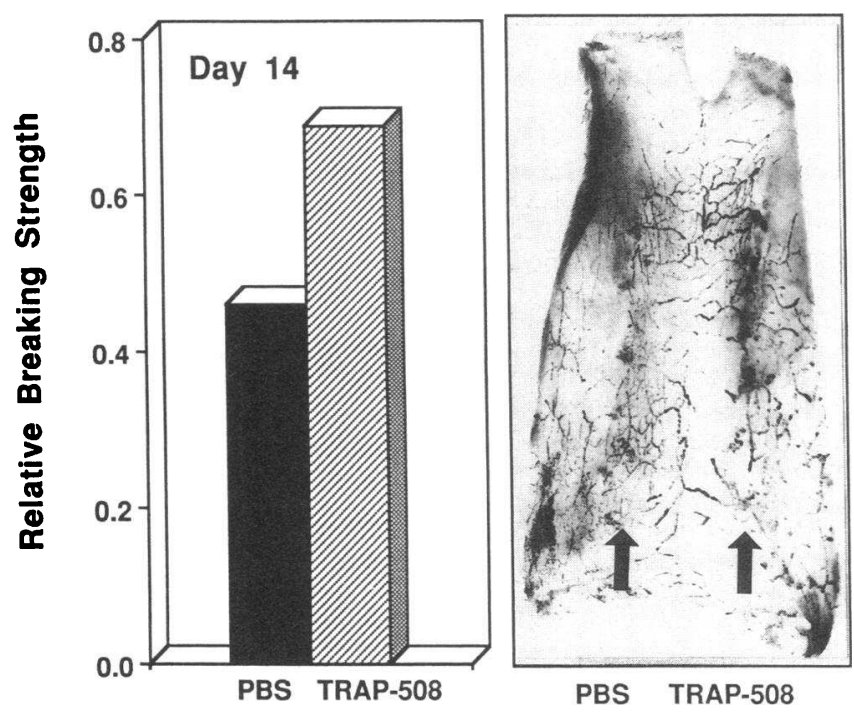

Figure 6. Comparison between TRAP-508 effects on incisional breaking strength and neovascularization in single rats. Two dorsal incisions were prepared, closed with four interrupted sutures, and treated with PBS on the left and TRAP-508 on the right as described in Table I. After 14 days, rats were anesthetized and radiopaque dye was injected into their circulatory system as described in Fig. 5. After dye injection the backs of the rats were removed, chilled, and x-rayed (in this case, without fixation), and then strips were cut perpendicular to the incisions to determine breaking strength as described in Fig. 1 and Methods. Arrows at the bottom (caudal) indicate the location and direction of each incision. and TRAP-508-treated wounds. Time course determinations indicate that control incisions would take $\sim 11.5$ days to acquire the breaking strength of TRAP-treated incisions at day 7 . Thus it appears that TRAP accelerates healing of these incisions by up to 4.5 days.

Enhancement of incisional breaking strength was observed in experiments with single or paired incisions. Interestingly, enhancement by TRAP appeared to be greatest in rats with two parallel incisions where control healing is slightly reduced. This may suggest that TRAP may be especially useful in accelerating healing under conditions where neovascularization or circulating inflammatory cells may be limited.

TRAP-508b, the bovine sequence of TRAP-508, appeared to be equivalent to human TRAP-508 in enhancement of breaking strength. This indicates that slight changes in the peptide do not appear to affect its activity. In contrast, treatment of wounds with a random short peptide or a truncated TRAP peptide had no observable stimulatory effect. Thus, enhancement of breaking strength appears specific for peptides with major portions of the unique TRAP sequence.

Angiography of rat backs 7 and 14 days after wounding showed complex patterns of microvasculature going into and transcending the incisional area of thrombin and TRAPtreated incision. Video graphic analysis indicated that $\sim 65 \%$ $(P<0.03)$ more blood vessels crossed TRAP-treated incisions than control incisions at day 7 . This angiogenic effect of thrombin and TRAP is consistent with recent demonstrations that thrombin stimulates proliferation of capillary endothelial cells (29) and that both thrombin and TRAP-508 are angiogenic when assayed on chicken chorioallantoic membranes (Lehman, T. J., and D. H. Carney, manuscript in preparation). Meltzer and Myers (51) reported stimulation of angiogenesis as well as increases in bursting strength in wounds after treatment with hyperbaric oxygen. Thus, promoting early angiogenesis may provide the metabolic environment necessary at the cellular level to boost proliferation and synthetic activity of wound fibroblasts.

The effects of exogenously added $\alpha$-thrombin and TRAP508 may begin with an acceleration of initial events involved in bringing inflammatory cells, fibroblasts, and endothelial cells into the wound. In separate experiments, we have radiolabeled TRAP-508 and followed its clearance from wounds. These studies indicate that $>90 \%$ of the radioactivity is cleared from the rat within the first $24 \mathrm{~h}$ (Redin, W. R., A. E. Ahmed and D. H. Carney, manuscript in preparation). Although some of the peptide may remain bound to cells, we anticipate that most of the stimulatory action of thrombin or the TRAP peptide 
occurs by promoting early events to shift forward the normal sequence of wound healing. As described previously, thrombin increases vascular permeability (52), and increases neutrophil and other cell adherence and extravasation across capillary endothelium (22). TRAP-508 also appears to advance the temporal accumulation of neutrophils in open wounds by $20-30 \%$ during the first two hours after wounding (Roark, L., L. McCroskey, and D. H. Carney, in preparation). Once these cells are attracted to the wound, thrombin or thrombin peptides may also stimulate release of other factors. For example, we have recently shown that thrombin activates $T$ cells and stimulates their synthesis and release of IL-6 (26). Such enhanced accumulation of inflammatory cells or their activation may then expedite neovascularization and promote earlier proliferative phases of wound healing.

It is important to recognize that exogenously added thrombin or TRAP most likely mimics normal effects of thrombin in initiating wound healing. Although active thrombin produced at the site of injury can be inactivated by antithrombin III or protease-nexin, it is also protected from inhibition by its sequestration within the fibrin clot (35) and binding to subendothelial extracellular matrix (36). Intact or partially degraded thrombin molecules, released as the clot is degraded, may then stimulate infiltration of inflammatory cells, or the subsequent migration and proliferation of epithelial cells, fibroblasts, and capillary endothelial cells. That TRAP-508 was slightly better than thrombin in enhancing incisional breaking strength in the present studies may reflect the ability of this peptide to circumvent inhibitory interactions which confront the intact thrombin molecule. Alternatively, based on recent three-dimensional analysis of thrombin, at least part of the TRAP sequence may only be exposed once thrombin is partially cleaved into derivative forms or peptide fragments (53). Thus, in the wound environment modified thrombin or active released peptides may be the primary activator of important postclotting cellular wound healing events.

It is noteworthy that thrombin and TRAP-508 significantly increase incisional breaking strength after only a single topical application in saline solution at the time of the surgical incision. Many other growth factors tested in similar models have proved effective only when administered in collagen gel or a slow release vehicle $(7,8,11)$. In other cases, growth factors have been injected into or under the skin adjacent to the wound three days after surgery (9). Our results suggest that much of the stimulatory effect caused by thrombin or TRAP would be well underway before this time. If one of our goals is to accelerate normal healing without risk of abnormal scar formation or latent (or systemic) effects of growth factors, then it may be important to look for factors such as thrombin or the thrombin peptides which appear to act through initiation of early events. The ability to synthesize peptides that select for specific wound healing properties of a molecule like thrombin may have vast potential in future studies to better understand the regulation of tissue repair. In addition, further development of these peptides may lead to new options for promotion and management of wound healing in man.

\section{Acknowledgments}

The authors wish to express their gratitude to Dr. Herndon and the Shriners Burns Center in Galveston for support of Dr. Mann; The University of Texas Medical Branch Histopathology Lab for histological sectioning and staining; Dr. J. A. Hokanson for statistical analysis: and Margie Clark-Wronsky and Rose Byrdlon-Griggs for administrative and secretarial support.

This work was supported in part by the National Institutes of Diabetes and Kidney Diseases (DK-25807 to D. H. Carney), Heart and Lung Institute (HL-13160 to J.W.Fenton II), The Texas Coordinating Board (Advanced Technology Program), and Monsanto.

\section{References}

1. Glenn, K. C., G. H. Frost, J. S. Bergmann, and D. H. Carney. 1988. Synthetic peptides bind to high-affinity thrombin receptors and modulate thrombin mitogenesis. Pept. Res. 1:65-73.

2. Leibovich, S. J., and R. Ross. 1975. The role of the macrophage in wound repair: a study with hydrocortisone and anti-macrophage serum. Am. J. Pathol. 78:71-91.

3. Hunt, T. K., D. R. Knighton, K. K. Thakral, W. Goodson, and W. S. Andrews. 1984. Studies on inflammation and wound healing: angiogenesis and collagen synthesis stimulated in vivo by resident and activated wound macrophgaes. Surgery (St. Louis). 96:48-54.

4. Rappolee, D. A., D. Mark, M. J. Banda, and Z. Werb. 1988. Wound macrophages express TGF-alpha and other growth factors in vivo: analysis by mRNA phenotyping. Science (Wash. DC). 241:708-712.

5. McGrath, M. H. 1990. Peptide growth factors and wound healing. Clin. Plast. Surg. 17:421-432.

6. Van Brunt, J., and A. Klausner. 1988. Growth factors speed wound healing. Bio/Technol. 6:25-30.

7. Mustoe, T. A., G. F. Pierce, A. Thomason, P. Gramates, M. B. Sporn, and T. F. Deuel. 1987. Accelerated healing of incisional wounds in rats induced by transforming growth factor-beta. Science (Wash. DC). 237:1333-1336.

8. Pierce, G. F., T. A. Mustoe, R. M. Senior, J. Reed, G. L. Griffin, A. Thomason, and T. F. Deuel. 1988. In vivo incisional wound healing augmented by platelet-derived growth factor and recombinant c-sis gene homodimeric proteins. J. Exp. Med. 167:974-987.

9. McGee, G. S., J. M. Davidson, A. Buckley, A. Sommer, S. C. Woodward, A. M. Aquino, R. Barbour, and A. A. Demetriou. 1988. Recombinant basic fibroblast growth factor accelerates wound healing. J. Surg. Res. 45:145-153.

10. McGee, G. S., K. N. Broadley, A. Buckley, A. Aquino, S. C. Woodward, A. A. Demetriou, and J. M. Davidson. 1989. Recombinant transforming growth factor beta accelerates incisional wound healing. Curr. Surg. 46:103-106.

11. Brown, G. L., L. J. Curtsinger, M. White, R. O. Mitchell, J. Pietsch, R. Nordquist, A. von Fraunhofer, and G. S. Schultz. 1988. Acceleration of tensile strength of incisions treated with EGF and TGF-beta. Ann. Surg. 208:788-794.

12. Malik, A. B. 1986. Thrombin-induced endothelial injury. Semin. Thromb. Hemostasis. 12:184-196.

13. Harlan, J. M., P. J. Thompson, R. R. Ross, and D. F. Bowen-Pope. 1986 Alpha-thrombin induces release of platelet-derived growth factor-like molecule(s) by cultured human endothelial cells. J. Cell Biol. 103:1129-1133.

14. Daniel, T. O., V. C. Gibbs, D. F. Milfay, M. R. Garovoy, and L. T. Williams. 1986. Thrombin stimulates c-sis gene expression in microvascular endothelial cells. J. Biol. Chem. 261:9579-9582.

15. Daniel, T. O., V. C. Gibbs, D. F. Milfay, and L. T. Williams. 1987. Agents that increase cAMP accumulation block endothelial c-sis induction by thrombin and transforming growth factor-beta. J. Biol. Chem. 262:11893-11896.

16. Prescott, S. M., G. A. Zimmerman, and T. M. McIntyre. 1984. Human endothelial cells in culture produce platelet-activating factor (1-alkyl-2-acetyl-snglycero-3-phosphocholine) when stimulated with thrombin. Proc. Natl. Acad. Sci. USA. 81:3534-3538.

17. Zimmerman, G. A., T. M. McIntyre, and S. M. Prescott. 1985. Thrombin stimulates the adherence of neutrophils to human endothelial cells in vitro. $J$. Clin. Invest. 76:2235-2246.

18. Zimmerman, G. A., T. M. McIntyre, and S. M. Prescott. 1986. Thrombin stimulates neutrophil adherence by an endothelial cell-dependent mechanism: characterization of the response and relationship to platelet-activating factor synthesis. Ann. NY Acad. Sci. 485:349-368.

19. Bizios, R., L. C. Lai, J. A. Cooper, P. J. Del Vecchio, and A. B. Malik. 1988. Thrombin-induced adherence of neutrophils to cultured endothelial monolayers: increased endothelial adhesiveness. J. Cell. Physiol. 134:275-280.

20. Bevilacqua, M. P., S. Stengelin, M. A. J. Gimbrone, and B. Seed. 1989. Endothelial leukocyte adhesion molecule 1: an inducible receptor for neutrophils related to complement regulatory proteins and lectins. Science (Wash. DC). 243:1160-1165.

21. Saegusa, Y., D. Cavender, and M. Ziff. 1988. Stimulation of mononuclear cell binding to human endothelial cell monolayers by thrombin. J. Immunol. 141:4140-4145.

22. Bizios, R., L. Lai, J. W. Fenton II, and A. B. Malik. 1986. Thrombin-induced chemotaxis and aggregation of neutrophils. J. Cell. Physiol. 128:485-490.

23. Bizios, R., L. Lai, J. W. Fenton II, S. A. Sonder, and A. B. Malik. 1985. 
Thrombin-induced aggregation of lymphocytes: non-enzymic induction by an hirudin-blocked thrombin exosite. Thromb. Res. 38:425-431.

24. Bar-Shavit, R., A. Kahn, J. W. Fenton II, and G. D. Wilner. 1983. Receptor-mediated chemotactic response of a macrophage cell line (J774) to thrombin. Lab. Invest. 49:702-707.

25. Bar-Shavit, R., A. J. Kahn, K. G. Mann, and G. D. Wilner. 1986. Growthpromoting effects of esterolytically inactive thrombin on macrophages. $J$. Cell. Biochem. 32:261-272.

26. Naldini, A., D. H. Carney, V. Bocci, and G. R. Klimpel. 1991. Thrombin enhances T cell activation. FASEB (Fed. Am. Soc. Exp. Biol.) J. 5:1378A

27. Chen, L. B., and J. M. Buchanan. 1975. Mitogenic activity of blood components. I. Thrombin and prothrombin. Proc. Natl. Acad. Sci. USA. 72:131135.

28. Carney, D. H., K. C. Glenn, and D. D. Cunningham. 1978. Conditions which affect initiation of animal cell division by trypsin and thrombin. J. Cell. Physiol. 95:13-22.

29. Perez-Rodriguez, R., A. Franchi and J. Pouyssegur. 1981. Growth factor requirements of Chinese hamster lung fibroblasts in serum-free media: high mitogenic reaction of thrombin. Cell Biol. Int. Rep. 5:347-357.

30. Pohjanpelto, P. 1977. Proteases stimulate proliferation of human fibroblasts. J. Cell. Physiol. 91:387-392.

31. Reddan, J., D. C. Dziedzic, and S. J. McGee. 1982. Thrombin induces cell division in rabbit lenses cultured in a completely defined serum-free medium. Invest. Opthalmol. \& Vis. Sci. 22:486-493.

32. Zetter, B. R., and H. N. Antoniades. 1979. Stimulation of human vascular endothelial cell growth by platelet-derived growth factor and thrombin. J. Supramol. Struct. 11:361-370.

33. Gospodarowitz, D., K. D. Brown, C. R. Birdwell, and B. R. Zetter. 1978. Control of proliferation of human vascular endothelial cells. Characterization of the response of human umbilical vein endothelial cells to fibroblast growth factor, epidermal growth factor and thrombin. J. Cell Biol. 77:774-788.

34. Belloni, P. N., D. H. Carney, and G. L. Nicolson. 1992. Organ-derived endothelial cells express differential responsiveness to thrombin and other growth factors. Microvasc. Res. 43:20-45.

35. Wilner, G. D., M. P. Danitz, M. S. Mudd, K.-H. Hsieh, and J. W. Fenton II. 1981. Selective immobilization of alpha-thrombin by surface-bound fibrin. $J$. Lab. Clin. Med. 97:403-411.

36. Bar-Shavit, R., A. Eldor, and I. Vlodavsky. 1989. Binding of thrombin to subendothelial extracellular matrix. Protection and expression of functional properties. J. C.in. Invest. 84:1096-1104.

37. Carney, D. H., and D. D. Cunningham. 1978. Role of specific cell surface receptors in thrombin-stimulated cell division. Cell. 15:1341-1349.

38. Carney, D. H., K. C. Glenn, D. D. Cunningham, M. Das, C. F. Fox, and
J. W. Fenton. 1979. Photoaffinity labeling of a single receptor for alpha-thrombin on mouse embryo cells. J. Biol. Chem. 254:6244-6247.

39. Frost, G. H., W. C. Thompson, and D. H. Carney. 1987. Monoclonal antibody to the thrombin receptor stimulates DNA synthesis in combination with gamma-thrombin or phorbol myristate acetate. J. Cell Biol. 105:2551-2558.

40. Perdue, J. F., W. Lubenskyi, E. Kivity, S. Sonder, and J. W. Fenton II.

1981. Protease mitogenic response of chick embryo fibroblasts and receptor binding/processing of human alpha-thrombin. J. Biol. Chem. 256:2767-2776.

41. Bar-Shavit, R., A. J. Kahn, K. G. Mann, and G. D. Wilner. 1986. Identification of a thrombin sequence with growth factor activity on macrophages. Proc. Natl. Acad. Sci. USA. 83:976-980.

42. Sonne, O. 1988. The specific binding of thrombin to human polymorphonuclear leucocytes. Scand. J. Clin. Lab. Invest. 48:831-838.

43. Vu, T.-K. H., D. T. Hung, V. I. Wheaton, and S. R. Coughlin. 1991 Molecular cloning of a functional thrombin receptor reveals a novel proteolytic mechanism of receptor activation. Cell. 64:1057-1068.

44. Fenton, J. W., II, M. J. Fasco, A. B. Stackrow, D. L. Aronson, A. M Young, and J. S. Finlayson. 1977. Human thrombins. Production, evaluation, and properties of alpha-thrombin. J. Biol. Chem. 252:3587-3595.

45. Russell, H. K. 1972. A modification of Movat's pentachrome stain. Arch Pathol. 94:187-191.

46. Prockop, D. J. 1981. Collagen biochemistry and the design of agents to inhibit excessive accumulation of collagen during wound repair. In The Surgical Wound. P. Dineen, and G. Hildick-Smith, editors. Lea and Febiger, Malvern.

47. Longacre, J. J. 1983. Scar Tissue: Its Use and Abuse. Charles C. Thomas, Publishers, Springfield, IL.

48. Fenton, J. W., II. 1988. Regulation of thrombin structure and function. Semin. Thromb. Hemostasis. 14:234-240.

49. Carney, D. H. 1987. Characterization of the thrombin receptor and its involvement in initiation of cell proliferation. In Control of Animal Cell Proliferation. A. L. Boynton, and H. L. Leffert, editors. Academic Press, Inc., Orlando, FL.

50. Carney, D. H. 1991. Postclotting cellular effects of thrombin mediated by interaction with high-affinity thrombin receptors. In Thrombin Structure and Function. L. Beliner, editor. Plenum Publishing Corp., New York.

51. Meltzer, T., and B. Myers. 1986. The effect of hyperbaric oxygen on the bursting strength and rate of vascularization of skin wounds in the rat. Am. Surg. 52:659-662.

52. Garcia, J. G., B. A. Siflinger, R. Bizios, V. P. J. Del, J. W. Fenton II, and A. B. Malik. 1986. Thrombin-induced increase in albumin permeability across the endothelium. J. Cell. Physiol. 128:96-104.

53. Rydel, T. J., K. G. Ravichandran, A. Tulinsky, W. Bode, R. Huber, C. Roitsch, and J. W. Fenton II. 1990. The structure of a complex of recombinant hirudin and human alpha thrombin. Science (Wash. DC). 249:277-280. 